\title{
Validation and Psychometric Properties of the Japanese Version of the Fear of COVID-19 Scale Among Adolescents
}

\author{
Akihiro Masuyama $^{1}$ (D) Hiroki Shinkawa ${ }^{2} \cdot$ Takahiro Kubo $^{3,4}$ (D) \\ Published online: 13 July 2020 \\ C) Springer Science+Business Media, LLC, part of Springer Nature 2020
}

\begin{abstract}
In the context of the global outbreak of COVID-19, there is an urgent need to explore the effects of this pandemic on the mental health of adolescents. The present study aims to adapt and validate a Japanese-version Fear of COVID-19 Scale (FCV-19S) with a sample of adolescent students from Japan. To this end, the Japanese-version FCV-19S, Generalized Anxiety Disorder 7-item scale (GAD-7), Patient Health Questionnaire for Adolescents (PHQ-A), and Perceived Vulnerability to Disease Scale (PVDS) were administered to a sample of Japanese adolescents in schools. The results of statistical analyses revealed that the Japanese-version FCV-19S has a bi-factor model consisting of the emotional response factor and the physiological response factor, with high reliability (emotional: $\alpha=.71$; physiological: $\alpha=.82$ ). Constructive validity was shown by the significant positive correlation between the GAD-7 and emotional $(r=.11)$ and physiological response $(r=.25)$, between PHQ-A and physiological response $(r=.19)$, and between both factors and the PVDS subscale $(r s>.16)$. Taken together, these results indicate that the Japanese-version FCV-19S has a high internal consistency and a moderately good construct validity.
\end{abstract}

Keywords COVID-19 $\cdot$ Fear of COVID-19 scale $\cdot$ Adolescents $\cdot$ Scale development

Akihiro Masuyama

ak.masuyama@gmail.com

1 Faculty of Psychology, Iryo Sosei University, Chuodai-Iino 5-5-1, Iwaki City, Fukushima 970-8551, Japan

2 Research Center for Child Mental Development, Graduate School of Medicine, Hirosaki University, Zaifu-cho 5, Hirosaki City, Aomori 036-8562, Japan

3 Psychological Counseling Center, Iryo Sosei University, Chuodai-Iino 5-5-1, Iwaki City, Fukushima 970-8551, Japan

4 Iwaki City Board of Education, Taira-Donemachi 4-8, Iwaki City, Fukushima 970-8026, Japan 


\section{Background}

The global crisis caused by the coronavirus pandemic 2019 (COVID-19) continues to escalate. According to the World Health Organization (WHO), infections have been confirmed in most countries of the world. As of May 28, the total number of deaths reached over 340,000 (WHO 2020a, May 28). In order to control COVID-19, most nations have implemented social distancing and self-isolation measures to restrict people from going outside and engaging in social activities. Furthermore, even in places where restrictions are lax, many people have concerns about being infected with COVID-19 (Lin 2020). Until now, the new regulations regarding our lifestyle, including social distancing, self-isolation, and wearing personal protective equipment, have shown to be effective in reducing the number of new COVID-19 infections (Shrivastava and Shrivastava 2020; Siedner et al. 2020); however, all these measures have resulted in dramatic changes in people's everyday lives.

Several studies have sought to explore the effects of these new social practices of social distancing and self-isolation on people's mental suffering, including mental health and other psychological aspects. For instance, Pancani et al. (2020) found that extended social isolation has worsened people's mental health in Italy. Furthermore, in a series of international surveys, Nelson et al. (2020) revealed that stringent self-quarantine behavior results in increased depression and anxiety. Likewise, an extensive review of previous research on the psychological impact of past pandemics - such as severe acute respiratory syndrome (SARS), Ebola, and H1N1 influenza - demonstrated that quarantine leads to poorer mental health and increased fear of infection (Brooks et al. 2020). Overall, during disease outbreaks, mental health issues and diseases can emerge or aggravate both directly, by the epidemic itself, and indirectly, i.e., as an effect of disease control measures (Lin and Cheng 2020). In this context, there is an urgent need to explore how the COVID-19 pandemic affects the mental health and psychological well-being of the world's population. However, until now, no such study has been conducted in Japan. Of note, in order to investigate the influence of the COVID-19 pandemic on mental health, one would need to investigate both pandemic-specific mental states and general mental health, such as depression and anxiety. Previous research on past pandemics demonstrated that the fear of infection plays an important role in people's mental health (Pappas et al. 2009) and preventive behaviors (Pakpour and Griffiths 2020). For instance, during the SARS pandemic, the fear of infection was found to be associated with post-traumatic stress symptoms (Ho et al. 2005), suggesting that fear of contracting a virus could lead to stress-related symptoms.

In response to the need of investigating the impact of the COVID-19 pandemic on the world's population, the Fear of COVID-19 Scale (FCV-19S) has been recently developed (Ahorsu et al. 2020). The FCV-19S is a valid and robust psychological assessment scale to evaluate the fear of COVID-19 (Pakpour et al. 2020). While the initial version of the scale was developed in Persian (Ahorsu et al. 2020), the instrument was then translated into several languages, including English (Ahorsu et al. 2020), Italian (Soraci et al. 2020), and Bangla (Sakib et al. 2020). Using the results of the FCV-19S in clinical treatment can contribute to patients' well-being. Used as a screening tool within the general population, the FCV-19S can also help to identify individuals and groups in need of targeted psychological support, such as counseling and psychotherapy.

Adolescents are a potentially vulnerable group in this respect. While the COVID-19 death rate in younger populations has been reported to be lower than among older people (WHO 2020b, May 29), adolescents suffer from social distancing and self-isolation caused by school 
closures and other dramatic changes in their environment. Accordingly, many researchers have appealed to the need for a long-term examination of and appropriate psychological care for adolescents in the emerging COVID-19 pandemic (Lee 2020; Viner et al. 2020). This need is reinforced by the evidence that, overall, worsened mental health in adolescents predicts the onset of mental disorders in adulthood (Fogel et al. 2006; Johnson et al. 2018). Indeed, a recent report has revealed that social distancing measures implemented during the COVID-19 pandemic are associated with depression and anxiety in adolescents (Oosterhoff et al. 2020).

Considering the evidence reviewed above and the lack of a Japanese version of the FCV$19 \mathrm{~S}$, the present study aims to produce an adapted Japanese version of the FCV-19S instrument and to validate it among the Japanese adolescent population. The adaptation of the Japanese version of the scale undertaken in this research is based on the original FCV-19S (Ahorsu et al. 2020) and its translated versions (Sakib et al. 2020; Satici et al. 2020; Soraci et al. 2020). The results of the present study contribute to the available literature on the association between the COVID-19 pandemic and mental health in Japan, as well as facilitate prospective global comparative research on mental health, including the fear of COVID-19.

\section{Method}

\section{Participants}

The data collection was performed in mid-May 2020 in two junior high schools in Japan. The survey was conducted in cooperation with the board of education and school principals of the two schools. The survey took place during designated classes in the two schools. Upon obtaining informed consent from all participants and the explanations of the teachers in charge of those classes, the students filled in the questionnaire. A total of 629 adolescents ( 309 females; mean age $=12.96, \mathrm{SD}=0.83$ ) participated in this study. All procedures involved in this study were approved by the ethics committee of Iryo Sosei University (\#20-02), the chairman of the board of education, and the school principals.

\section{FCV-19S Scale Translation}

The English version of the FCV-19S (Ahorsu et al. 2020) was translated into Japanese following the guidelines of the International Society for Pharmacoeconomics and Outcomes Research Task Force (Wild et al. 2005). First, two psychologists independently translated the seven items of the FCV-19S from English to Japanese. Second, these two translations were integrated into one and backtranslated into English by another English/Japanese speaker without prior knowledge of the FCV19S. The process of back-translation confirmed the equivalence between the original version (Ahorsu et al. 2020) and the Japanese translation. The Japanese FCV-19S was then piloted among several adolescent individuals. After minor modifications suggested by the pilot pretest, the final version of the Japanese FCV-19S was produced.

\section{Measures}

\section{Fear of COVID-19 Scale}

The Japanese-version Fear of COVID-19 Scale (FCV-19S) was used to measure the participants' fear in relation to the COVID-19 infection (Appendix). This unifactor instrument 
consisted of seven items to be rated on a 5-point scale ( 1 = "strongly disagree"; 5 = "strongly agree"). Therefore, the total score ranged from 7 to 35 , with a higher score indicating a greater fear of COVID-19. The satisfactory internal consistency and validation of the scale were confirmed in the original version of the scale ( $\alpha=.82$; Ahorsu et al. 2020).

\section{Generalized Anxiety Disorder 7-Item Scale}

The Japanese version of the Generalized Anxiety Disorder (GAD-7; Spitzer et al. 2006), validated by Muramatsu et al. (2009), was used to measure the participants' anxiety symptoms. The unifactor GAD-7 consists of seven items to be rated on a 4-point scale ( 1 = "not at all"; $4=$ "nearly every day"). The total score ranged from 0 to 21 , with higher values indicating more severe anxiety. The internal consistency of the scale was excellent $(\alpha=.92$; Muramatsu et al. 2009).

\section{Patient Health Questionnaire for Adolescents}

The Japanese version of the Patient Health Questionnaire for Adolescents (PHQ-A; Johnson et al. 2002) was used to measure the participants' depressive symptoms. The PHQ-A consists of nine items to be rated on a 4-point scale ranging from $1=$ "not at all" to $4=$ "nearly every day." The total score ranged from 0 to 27 , with higher scores indicating stronger depressive symptoms.

\section{Perceived Vulnerability to Disease Scale}

The Japanese-version Perceived Vulnerability to Disease Scale (PVDS) was used to measure the participants' perceived vulnerability to disease and infection. The PVDS consists of 15 items and has a two-factor structure: perceived infectability (seven items) and germ aversion (eight items). The participants responded to each item on a 7-point scale ranging from $1=$ "strongly disagree" to $7=$ "strongly agree." The total scores ranged from 7 to 49 (perceived infectability) and 8 to 56 (germ aversion), with higher scores indicating greater perceived vulnerability. This scale was previously reported to have acceptable internal consistency ( $\alpha=.87, .67$, and .79; perceived infectability, germ aversion, and total score respectively; Fukukawa et al. 2014).

\section{Data Analyses}

To verify the structural validity of the Japanese version of the FCV-19S, a confirmatory factor analysis (CFA) with the diagonally weighted least squares (DWLS) estimation was performed. The following indices of model fit were considered: comparative fit index (CFI), root mean square error of approximation (RMSEA), and standardized root mean square residual (SRMR). Following Schermelleh-Engel et al. (2003), an acceptable fit criterion was regarded as $\mathrm{CFI}>.95$, RMSEA $<.08$, and $\mathrm{SRMR}<.10$; a good fit criterion was regarded as a CFI > .97, RMSEA $<.05$, and SRMR $<.05$.

The reliability of the Japanese version of the FCV-19S was evaluated using Cronbach's alpha. To examine construct validity, we calculated Pearson's correlation coefficients with the comparison measures (i.e., the score of the GAD-7, PHQ-A, and PVDS). The strength of the correlation was determined following Andresen (2000) where $r<.30$ was "weak," $r=.30-.59$ 
was "moderate," and $r \geq .60$ was "strong." The participants with missing values were excluded from all analyses. Statistical analyses were performed using IBM SPSS Statistics 25 and R ver. 4.0.1 with the lavaan package (Rosseel 2012).

\section{Results}

Descriptive statistics of the Japanese-version FCV-19S - including mean, standardized deviation, skewness, kurtosis, and floor/ceiling effects - are summarized in Table 1. The skewness and kurtosis values in all items ranged from -2 to +2 , except for the kurtosis value in item 6 . For items 3,6 , and 7 , over $65 \%$ of the respondents reported the lowest scores, indicating a possibility of the floor effect. However, overall Cronbach's alpha was .82 (see below for further discussion). These results suggested that the Japanese-version of the FCV-19S has a good detectability regarding change and variance of fear of COVID-19.

The results of the CFA to verify the structural validity of the Japanese version of the FCV$19 \mathrm{~S}$ are summarized in Table 2. The indices showed that the bi-factor model was the best fit for our data $(\mathrm{CFI}=.997$, RMSEA $=.034, \mathrm{SRMR}=.040)$, compared with the single-factor model $(\mathrm{CFI}=.952, \mathrm{RMSEA}=.103, \mathrm{SRMR}=.106)$ and the two-factor model $(\mathrm{CFI}=.983$, RMSEA = .064, SRMR =.064). Therefore, we adopted the bi-factor model as an integrated model with an original general factor (Ahorsu et al. 2020) and two-factor model consisting of the "emotional response" factor (items 1,2, 4, and 5) and "physiological response" factor (items 3, 6, and 7). In this decision, we followed a previous study by Reznik et al. (2020) using the Russian version of the FCV-19S in Russia and Belarus. Indeed, our results are consistent with those reported by Reznik et al. (2020) in that the estimates were .561 or higher, suggesting a robust construction of each factor. The statistics for each factor are summarized in Table 1. Furthermore, Cronbach's alphas of the Japanese-version FCV-19S were .82 in total, .71 in emotional response, and .82 in physiological response, suggesting that both factors had sufficiently high reliability.

To test the construct validity of the Japanese-version FCV-19S, a correlation analysis was performed on each variable (Table 3). The results showed that the correlation coefficients between each factor of the Japanese-version FCV-19S and each of the factors in the PVDS ranged from .16 to $.25(p<.001)$, suggesting that both the emotional and physiological fear responses towards COVID-19 were related to the perception of one's vulnerability to disease. Furthermore, the results of correlation analysis showed that depressive symptoms significantly

Table 1 Descriptive statistics of the Japanese version of the FCV-19S

\begin{tabular}{llllllll}
\hline FCV-19S & $N$ & Mean & $S D$ & Skewness & Kurtosis & Floor (\%) & Ceiling (\%) \\
\hline Item 1 & 629 & 4.04 & 1.19 & -1.35 & 0.94 & 7.47 & 44.99 \\
Item 2 & 627 & 3.39 & 1.37 & -0.50 & -0.98 & 14.83 & 24.72 \\
Item 3 & 627 & 1.61 & 0.98 & 1.55 & 1.58 & 65.87 & 1.59 \\
Item 4 & 628 & 3.89 & 1.32 & -1.04 & -0.11 & 10.35 & 44.43 \\
Item 5 & 629 & 2.81 & 1.35 & -0.01 & -1.30 & 24.64 & 10.33 \\
Item 6 & 627 & 1.46 & 0.85 & 1.90 & 3.06 & 71.61 & 0.80 \\
Item 7 & 629 & 1.54 & 0.96 & 1.70 & 1.89 & 70.91 & 1.11 \\
Emotional response & 626 & 14.14 & 4.29 & -0.71 & -0.31 & 4.31 & 6.23 \\
Physiological response & 626 & 4.61 & 2.23 & 1.56 & 2.26 & 50.64 & 0.32 \\
Total score & 623 & 18.71 & 5.65 & -0.13 & -0.30 & 4.33 & 0.32 \\
\hline
\end{tabular}


Table 2 Model comparisons of the FCV-19S based on confirmatory analyses

\begin{tabular}{lllllll}
\hline Model & $\chi^{2}$ & $d f$ & $p$ value & CFI & RMSEA & SRMR \\
\hline Single-factor model & 106.526 & 14 & $<.001$ & .952 & .103 & .106 \\
Two-factor model & 46.129 & 13 & $<.001$ & .983 & .064 & .060 \\
Bi-factor model & 13.773 & 8 & .088 & .997 & .034 & .040 \\
\hline
\end{tabular}

correlated with physiological response $(r=.19)$, while anxiety symptoms significantly correlated with emotional response $(r=.11)$, physiological response $(r=.25)$, and overall fear of COVID-19 $(r=.18$; all $p$ values <.001). Taken together, these results indicate that the Japanese-version FCV-19S has a moderately good construct validity to measure the fear of COVID-19. Overall, compared with Ahorsu et al. (2020), we obtained relatively lower correlation coefficients between the fear of COVID-19 and each variable. This inconsistency of correlation coefficients with other versions of the FCV-19S instrument (Ahorsu et al. 2020; Sakib et al. 2020; Soraci et al. 2020) could be attributed to the influence of the biases in distribution that were observed in the PHQ-A (skewness $=1.55$, kurtosis $=3.02$ ) and GAD-7 ( skewness $=2.18$, kurtosis $=6.22$ ).

In summary, despite several floor effects in the data, the results demonstrated that the Japanese version of the FCV-19S has a bi-factor model: emotional response (items 1, 2, 4, and 5), physiological response (items 3,6, and 7), and general factor (overall), with a sufficiently high internal confidence and a moderately good construct validity.

\section{Discussion}

The present study aimed to produce a Japanese version of the FCV-19S and validate it among Japanese adolescents. The results of statistical analyses revealed that the Japanese version of the FCV-19S has a bi-factor model; high internal consistency in the emotional response factor, physiological response factor, and general factor; and a moderately good construct validity. Based on these results, it can be concluded that the Japanese version of the FCV-19S is a valid instrument to measure the fear of COVID-19 among Japanese adolescents.

Table 3 Correlations between the FCV-19S and comparison variables

\begin{tabular}{|c|c|c|c|c|c|c|}
\hline & \multicolumn{6}{|l|}{ FCV-19S } \\
\hline & \multicolumn{2}{|l|}{ Emotional } & \multicolumn{2}{|l|}{ Physiological } & \multicolumn{2}{|l|}{ Total score } \\
\hline \multicolumn{7}{|l|}{ FCV-19S } \\
\hline Emotional response & 1.00 & & & & & \\
\hline Physiological response & .45 & $* * *$ & 1.00 & & & \\
\hline Total score & .94 & $* * *$ & .74 & $* * *$ & 1.00 & \\
\hline \multicolumn{7}{|l|}{ PVDS } \\
\hline Perceived infectability & .16 & $* * *$ & .20 & $* * *$ & .20 & $* * *$ \\
\hline Germ aversion & .19 & $* * *$ & .25 & $* * *$ & .24 & $* * *$ \\
\hline Total score & .12 & $* *$ & .20 & $* * *$ & .17 & $* * *$ \\
\hline PHQ-A & .00 & & .19 & $* * *$ & .08 & \\
\hline GAD-7 & .11 & $* *$ & .25 & $* * *$ & .18 & $* * *$ \\
\hline
\end{tabular}

$* p<.05, * * p<.01, * * * p<.001$ 
The results of the CFA showed that the bi-factor model was the best fit for our data. This result is not in line with the findings reported in previous studies using other versions of the scale, such as Persian (Ahorsu et al. 2020), Bangla (Sakib et al. 2020), Italian (Soraci et al. 2020), Turkish (Satici et al. 2020), and Arabic (Alyami et al. 2020); all these studies found that the unifactor model was the best fit. However, our results are consistent with Reznik et al.'s (2020) study that administered the Russian version of the FCV-19S in Russia and Belarus. Furthermore, according to Alyami et al. (2020), the factor loads of items 3, 6, and 7-which were assigned to the physiological response factor in the present study and in Reznik et al. (2020)-had lower mean values than the remaining items. Therefore, taking into account the symptoms described in items 3, 6, and 7 (clammy hands, sleep disturbance, and palpitation due to COVID19), it can be concluded that fear-related somatic symptoms would be less experienced by the participants, as somatic symptoms were specific to a severe state of fear of COVID-19.

The results of correlation analysis performed to confirm construct validity revealed that emotional response in the FCV-19S significantly correlated with physiological response $(r=.45)$ and total score $(r=.94)$ in the FCV-19S, perceived infectability $(r=.16)$, germ aversion $(r=.19)$, and anxiety $(r=.11)$ and that physiological response significantly correlated with perceived infectability $(r=.20)$, germ aversion $(r=.25)$, depression $(r=.19)$, and anxiety $(r=.25)$. These results suggest that the emotional and physiological aspects of the fear of COVID-19 measured by the Japanese version of the FCV-19S are related to mental health and the perception of one's vulnerability to the disease. Although the significance and direction of the correlations in our results were largely consistent with those obtained using the original version and other translated versions of the FCV-19S, correlation coefficients in our results were lower than those found in previous studies. This outcome can be attributed to the following two reasons. First, while we administered the FCV-19S among adolescents, other studies used the scale to survey adult populations. Accordingly, divergences between our and previous studies could be related to qualitative differences in the underlying association between the fear of COVID-19 and mental health in adolescents vs. adults. Second, the aforementioned divergence could be attributed to the fact that, compared with most European countries, Japan has been less affected by COVID-19 (i.e., fewer infections and cases of death). Accordingly, the pandemic could have had a weaker impact on mental health in Japan. Overall, despite the somewhat lower values, our results demonstrated that the Japanese version of the FCV-19S has moderately good construct validity.

The contribution of the present study is twofold. First, to the best of our knowledge, our study is the first to apply the FCV-19S to adolescents. Despite the relatively lower health risks associated with COVID-19 in this population, adolescents are nevertheless psychologically vulnerable to the negative effects of the measures implemented to curb the pandemic, such as school closures, enhancing social distancing, and online learning. This brings about the need to investigate how quarantine strategies affect adolescents' mental health (Golberstein et al. 2020; Viner et al. 2020; WHO 2020b, May 29), as well as to elaborate appropriate strategies, such as school-based psychoeducation and/or group psychotherapy, that would help adolescents cope with psychological issues caused by the pandemic.

Second, the present study is the first to produce and validate the Japanese version of the FCV-19S. This version complements those already available in other languages - such as 
Persian (original version; Ahorsu et al. 2020), English (Ahorsu et al. 2020), Bangla (Sakib et al. 2020), Italian (Soraci et al. 2020), Turkish (Satici et al. 2020), Arabic (Alyami et al. 2020), and Greek (Tsipropoulou et al. 2020) - and facilitates prospective global comparative research on mental health, including the fear of COVID-19.

\section{Limitations}

The present study has several limitations. Firstly, as mentioned in the "Results" section, floor effects were found in the PHQ-A and GAD-7. This might be the result of underachieving construct validity in the Japanese version of the FCV-19S. Further research that would measure mental health by a wide range in the Japanese healthy adolescent population would be needed. Secondly, our data sample was limited to students of two junior high schools located in one prefecture with a relatively low total number of confirmed COVID-19 cases (specifically, 81 cases as of May 28). Therefore, it is possible that the participants of the present study were less concerned about COVID-19 compared with comparable adolescent cohorts from European countries or from other areas in Japan that have been more affected by the coronavirus. Finally, in the present study, we did not explore the possibility that school closures and online learning could have improved the participants' mental health through the elimination of many school-driven stressors, such as bullying, interacting with others, upcoming tests, and class participation. Therefore, in future studies, it would be necessary to investigate the psychological effects of school closures from the perspective of educational psychology.

\section{Conclusion}

The present study adapted and validated the Japanese version of the Fear of COVID-19 Scale (FCV-19S) in a sample of Japanese adolescents. Factor analysis of the participants' responses yielded a bi-factor model, with one dimension being the emotional response and the other dimension the physiological response. This model was found to have a high internal consistency (emotional: $\alpha=.71$; physiological: $\alpha=.82$ ) and moderately good construct validity. Further research on the impact of COVID-19 pandemic on the mental health of both the general population and adolescents is needed.

Acknowledgements The survey of the study was conducted with supporting by Iwaki city board of education. Especially, we are grateful to Mr. Yoshida Takashi (chairman of board of education) and Mr. Watanabe Nobutaka (general manager in Office for Support of Education in Education Center) for coordination and management of the survey in the schools.

Authors' Contribution Study planning: authors AM, HS, and TK; data collection: authors AM and TK; data analysis: authors AM and HS; writing the manuscript: author AM; review and editing: authors HS and TK.

Data Availability The data of this study will be available on request.

\section{Compliance with Ethical Standards}

All the procedures followed were in accordance with the ethical standards of the responsible committee on human experimentation (institutional and national) and with the Declaration of Helsinki. 
Disclaimer The authors involved in this research communication do not have any relationships with other people or organizations that could inappropriately influence (bias) the findings.

Conflict of Interest The authors declare that they have no conflict of interest.

Informed Consent All participants provided informed consent.

\section{Appendix. The Japanese-version Fear of COVID-19 Scale}

(新型コロナウイルス恐怖尺度)

以下の文章は現在流行している新型コロナウイルス（COVID-19、新型コロナ、新型型势焚）に 関するものです。それぞれの文章をよく読んで、ここ2週間のあなたの気持ちや考えに もっとも近いと思う番号に○をつけてください。

\begin{tabular}{|c|c|c|c|c|c|}
\hline & $\begin{array}{l}\text { まったく } \\
\text { あてはまら } \\
\quad \text { ない }\end{array}$ & $\begin{array}{l}\text { あまり } \\
\text { あてはまら } \\
\text { ない }\end{array}$ & $\begin{array}{c}\text { どちらでも } \\
\text { ない }\end{array}$ & $\begin{array}{c}\text { すこし } \\
\text { あてはまる }\end{array}$ & $\begin{array}{c}\text { とても } \\
\text { あてはまる }\end{array}$ \\
\hline 1 新型コロナウイルスをとても恐いと感じる & 1 & 2 & 3 & 4 & 5 \\
\hline 2 新型コロナウイルスのことを考えると、いやな気持ちになる & 1 & 2 & 3 & 4 & 5 \\
\hline 3 新型コロナウイルスのことを考えると、手に冷たい汗をかく & 1 & 2 & 3 & 4 & 5 \\
\hline 4 新型コロナウイルスによって命を失ってしまうことが怖い & 1 & 2 & 3 & 4 & 5 \\
\hline $\begin{array}{l}\text { メディア（テレビやインターネットなど）で } \\
5 \text { 新型コロナウイルスに関するニュースや話を見聞きすると、 } \\
\text { そわそわしたり、不安になったりする }\end{array}$ & 1 & 2 & 3 & 4 & 5 \\
\hline $6 \begin{array}{l}\text { 新型コロナウイルスにかかってしまうのでは、と } \\
\text { 心配になって眠れない }\end{array}$ & 1 & 2 & 3 & 4 & 5 \\
\hline 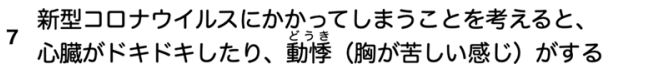 & 1 & 2 & 3 & 4 & 5 \\
\hline
\end{tabular}

\section{References}

Ahorsu, D. K., Lin, C. Y., Imani, V., Saffari, M., Griffiths, M. D., \& Pakpour, A. H. (2020). The Fear of COVID19 Scale: development and initial validation. International journal of mental health and addiction. https://doi.org/10.1007/s11469-020-00270-8.

Alyami, M., Henning, M., Krägeloh, C. U., \& Alyami, H. (2020). Psychometric evaluation of the Arabic version of the Fear of COVID-19 Scale. International journal of mental health and addiction. https://doi. org/10.1007/s11469-020-00316-x.

Andresen, E. M. (2000). Criteria for assessing the tools of disability outcomes research. Archives of Physical Medicine and Rehabilitation, 81, S15-S20. https://doi.org/10.1053/apmr.2000.20619.

Brooks, S. K., Webster, R. K., Smith, L. E., Woodland, L., Wessely, S., Greenberg, N., \& Rubin, G. J. (2020). The psychological impact of quarantine and how to reduce it: rapid review of the evidence. The Lancet, 395 , 912-920. https://doi.org/10.1016/S0140-6736(20)30460-8.

Fogel, J., Eaton, W. W., \& Ford, D. E. (2006). Minor depression as a predictor of the first onset of major depressive disorder over a 15-year follow-up. Acta Psychiatrica Scandinavica, 113(1), 36-43. https://doi. org/10.1111/j.1600-0447.2005.00654.x. 
Fukukawa, Y., Oda, R., Usami, H., \& Kawahito, J. (2014). Development of a Japanese version of the Perceived Vulnerability to Disease Scale. The Japanese journal of Psychology, 85, 188-195. https://doi.org/10.4992 /jjpsy.85.13206.

Golberstein, E., Wen, H., \& Miller, B. F. (2020). Coronavirus disease 2019 (COVID-19) and mental health for children and adolescents. JAMA pediatrics. https://doi.org/10.1001/jamapediatrics.2020.1456.

Ho, S. M., Kwong-Lo, R. S., Mak, C. W., \& Wong, J. S. (2005). Fear of severe acute respiratory syndrome (SARS) among health care workers. Journal of Consulting and Clinical Psychology, 73(2), 344. https://doi. org/10.1037/0022-006X.73.2.344-349.

Johnson, J. G., Harris, E. S., Spitzer, R. L., \& Williams, J. B. W. (2002). The patient health questionnaire for adolescents: validation of an instrument for the assessment of mental disorders among adolescent primary care patients. The Journal of Adolescent Health : Official Publication of the Society for Adolescent Medicine, 30(3), 196-204. https://doi.org/10.1016/S1054-139X(01)00333-0.

Johnson, D., Dupuis, G., Piche, J., Clayborne, Z., \& Colman, I. (2018). Adult mental health outcomes of adolescent depression: a systematic review. Depression and Anxiety, 35(8), 700-716. https://doi.org/10.1002 /da.22777.

Lee, J. (2020). Mental health effects of school closures during COVID-19. The Lancet Child \& Adolescent Health, 4(6), 421. https://doi.org/10.1016/S2352-4642(20)30109-7.

Lin, C. Y. (2020). Social reaction toward the 2019 novel coronavirus (COVID-19). Social Health and Behavior, 3(1), 1-2 http://www.shbonweb.com/text.asp?2020/3/1/1/280554.

Lin, M. W., \& Cheng, Y. (2020). Policy actions to alleviate psychosocial impacts of COVID-19 pandemic: experiences from Taiwan. Social Health and Behavior, 3(2), 72-73 http:/www.shbonweb.com/text. asp?2020/3/2/72/286260.

Muramatsu, K., Muramatsu, Y., Miyaoka, H., Fuse, K., Yoshimine, F., Hosaka, M., et al. (2009). Validation and utility of a Japanese version of the GAD-7. Panminerva Medica 20th World Congress on Psychosomatic Medicine. Abstract Book, 51(Suppl.1-3), 79.

Nelson, B. W., Pettitt, A., Flannery, J. E., \& Allen, N. B. (2020). Rapid assessment of psychological and epidemiological predictors of COVID-19 concern, financial strain, and health-related behavior change in a large online sample. PsyArXiv. https://psyarxiv.com/jftze/.

Oosterhoff, B., Palmer, C. A., Wilson, J., \& Shook, N. (2020). Adolescents' motivations to engage in social distancing during the COVID-19 pandemic: associations with mental and social health. Journal of Adolescent Health. https://doi.org/10.1016/j.jadohealth.2020.05.004.

Pakpour, A. H., \& Griffiths, M. D. (2020). The fear of COVID-19 and its role in preventive behaviors. Journal of Concurrent Disorders. http://irep.ntu.ac.uk/id/eprint/39561.

Pakpour, A. H., Griffiths, M. D., \& Lin, C. Y. (2020). Assessing psychological response to the COVID-19: the Fear of COVID-19 Scale and the COVID Stress Scales. International Journal of Mental Health and Addiction. https://doi.org/10.1007/s11469-020-00334-9.

Pancani, L., Marinucci, M., Aureli, N., \& Riva, P. (2020). Forced social isolation and mental health: a study on 1006 Italians under COVID-19 lockdown. PsyArXiv. https://doi.org/10.31234/osf.io/uacfj.

Pappas, G., Kiriaze, I. J., Giannakis, P., \& Falagas, M. E. (2009). Psychosocial consequences of infectious diseases. Clinical microbiology and infection: the official publication of the European Society of Clinical Microbiology and Infectious Diseases, 15(8), 743-747. https://doi.org/10.1111/j.1469-0691.2009.02947.x.

Reznik, A., Gritsenko, V., Konstantinov, V., Khamenka, V., \& Isralowitz, R. (2020). COVID-19 fear in Eastern Europe: validation of the Fear of COVID-19 Scale. International journal of mental health and addiction. https://doi.org/10.1007/s11469-020-00283-3.

Rosseel, Y. (2012). lavaan: An R package for structural equation modeling. Journal of Statistical Software, 48(2), 1-36. https://doi.org/10.18637/jss.v048.i02.

Sakib, N., Bhuiyan, A. I., Hossain, S., Al Mamun, F., Hosen, I., Abdullah, A. H., et al. (2020). Psychometric validation of the Bangla Fear of COVID-19 Scale: confirmatory factor analysis and Rasch analysis. International Journal of Mental Health and Addiction. https://doi.org/10.1007/s1 1469-020-00289-x.

Satici, B., Gocet-Tekin, E., Deniz, M. E., \& Satici, S. A. (2020). Adaptation of the Fear of COVID-19 Scale: its association with psychological distress and life satisfaction in Turkey. International Journal of Mental Health and Addiction. https://doi.org/10.1007/s11469-020-00294-0.

Schermelleh-Engel, K., Moosbrugger, H., \& Müller, H. (2003). Evaluating the fit of structural equation models: tests of significance and descriptive goodness-of-fit measures. Methods of Psychological Research Online, 8 , 23-74.

Shrivastava, S. R., \& Shrivastava, P. S. (2020). COVID-19 pandemic: responding to the challenge of global shortage of personal protective equipment. Social Health and Behavior, 3(2), 70-71 http://www.shbonweb. com/text.asp?2020/3/2/70/286259.

Siedner, M. J., Harling, G., Reynolds, Z., Gilbert, R. F., Venkataramani, A., \& Tsai, A. C. (2020). Social distancing to slow the US COVID-19 epidemic: an interrupted time-series analysis. medRxiv. 
Soraci, P., Ferrari, A., Abbiati, F. A., Del Fante, E., De Pace, R., Urso, A., \& Griffiths, M. D. (2020). Validation and psychometric evaluation of the Italian version of the Fear of COVID-19 Scale. International Journal of Mental Health and Addiction. https://doi.org/10.1007/s11469-020-00277-1.

Spitzer, R. L., Kroenke, K., Williams, J. B., \& Löwe, B. (2006). A brief measure for assessing generalized anxiety disorder: the GAD-7. Archives of Internal Medicine, 166, 1092-1097. https://doi.org/10.1001 /archinte.166.10.1092.

Tsipropoulou, V., Nikopoulou, V. A., Holeva, V., Nasika, Z., Diakogiannis, I., Sakka, S., Kostikidou, S., Varvara, C., Spyridopoulou, E., \& Parlapani, E. (2020). Psychometric properties of the Greek version of FCV-19S. International Journal of Mental Health and Addiction. https://doi.org/10.1007/s11469-02000319-8.

Viner, R. M., Russell, S. J., Croker, H., Packer, J., Ward, J., Stansfield, C., et al. (2020). School closure and management practices during coronavirus outbreaks including COVID-19: a rapid systematic review. The Lancet Child \& Adolescent Health, 4(5), 397-404. https://doi.org/10.1016/S2352-4642(20)30095-X.

Wild, D., Grove, A., Martin, M., Eremenco, S., McElroy, S., Verjee-Lorenz, A., \& Erikson, P. (2005). Principles of good practice for the translation and cultural adaptation process for patient-reported outcomes (PRO) measures: report of the ISPOR task force for translation and cultural adaptation. Value in Health, 8(2), 94 104. https://doi.org/10.1111/j.1524-4733.2005.04054.x.

World Health Organization. (2020a). Coronavirus disease (COVID-2019) situation reports. https://www.who. int/emergencies/diseases/novel-coronavirus-2019/situation-reports/.

World Health Organization. (2020b). COVID-19: Resources for Adolescents and Youth. https://www.who. int/maternal_child_adolescent/links/covid-19-mncah-resources-adolescents-and-youth/en/.

Publisher's Note Springer Nature remains neutral with regard to jurisdictional claims in published maps and institutional affiliations. 